\title{
The Clinical Effect of an Early, Protocolized Approach to Mechanical Ventilation for Severe and Refractory Hypoxemia
}

\author{
Alice Gallo de Moraes, Steven R Holets, Ann N Tescher, Jennifer Elmer, Grace M Arteaga, \\ Gregory Schears, Richard K Patch, John K Bohman, and Richard A Oeckler
}

\begin{abstract}
BACKGROUND: ARDS remains a source of significant morbidity and mortality in the critically ill patient. The mainstay of therapy entails invasive mechanical ventilation utilizing a lung-protective strategy designed to limit lung injury associated with excessive stress and strain while the underlying etiology of respiratory failure is identified and treated. Less is understood about what to do once conventional ventilation parameters have been optimized but the patient's respiratory status remains unchanged or worsens. In 2015, a protocolized, stepwise approach to mechanical ventilation with partially automated and clearly defined thresholds for management changes was implemented at our institution. We hypothesized that, by identifying appropriate patients earlier, time-to-escalation and rescue therapy implementation would be shortened. METHODS: Subjects with severe ARDS, treated with prone positioning based on our institution's protocolized approach from December 2013 to August 2016 were included. Their baseline characteristics, severity of illness scores, and mechanical ventilation parameters were collected and analyzed. RESULTS: Baseline characteristics, tidal volumes, $\mathrm{P}_{\mathrm{aO}} / \mathrm{F}_{\mathrm{IO}_{2}}$, duration of ventilation after proning, and mortality were similar in both groups. Median (interquartile range [IQR]) PEEP at the time of proning was higher after the protocol implementation $\left(12.5 \mathrm{~cm} \mathrm{H}_{2} \mathrm{O}\right.$ [IQR 6.5-19.4] vs $18 \mathrm{~cm} \mathrm{H}_{2} \mathrm{O}$ [IQR 10-22], $P=.386$ ), and mean (IQR) respiratory system driving pressure

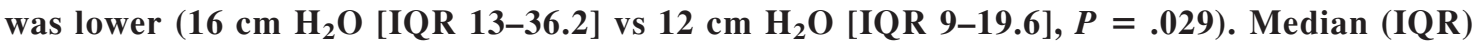
time from refractory hypoxemia identification to proning was shorter after protocol implementation (42.2 h [IQR 6.83-347.2] vs $16.3 \mathrm{~h}$ [IQR 1-99.7], $I=.02)$, and $\mathrm{P}_{\mathrm{aO}_{2}} / \mathrm{F}_{\mathrm{IO}_{2}}$ at $1 \mathrm{~h}$ after proning was higher. ICU and hospital LOS were shorter after the protocol implementation. CONCLUSIONS: Following the implementation of an early, evidencebased, protocolized approach to optimizing mechanical ventilation, subjects with true refractory hypoxemia were identified earlier and time to proning was significantly shorter. Despite improvement in the evaluation and management of refractory hypoxemia as well as time to initiation of prone positioning, mortality was unchanged and there was variation in the duration of the position. Key words: refractory hypoxemia; ARDS; prone position; protocolized mechanical ventilation. [Respir Care 2020;65(4):413-419. (C) 2020 Daedalus Enterprises]
\end{abstract}

Drs Gallo de Moraes, Patch, and Oeckler are affiliated with the Department of Medicine, Division of Pulmonary and Critical Care, Mayo Clinic, Rochester, Minnesota. Mr Holets is affiliated with the Department of Respiratory Care, Mayo Clinic, Rochester, Minnesota. Ms Tescher and Ms Elmer are affiliated with the Department of Nursing, Mayo Clinic, Rochester, Minnesota. Drs Schears, Patch, and Bohman are affiliated with the Department of Anesthesiology and
Perioperative Medicine, Division of Critical Care, Mayo Clinic, Rochester, Minnesota. Dr Arteaga is affiliated with the Department of Pediatrics and Adolescent Medicine, Division of Pediatric Critical Care, Mayo Clinic, Rochester, Minnesota.

Dr Gallo de Moraes presented preliminary data from this study at the 2018 American Thoracic Society International Conference, held May 18-23, 2018, in San Diego, California. 


\section{Early Protocolized Mechanical Ventilation in ARDS}

\section{Introduction}

Despite extensive investigation, ARDS remains a source of significant morbidity and mortality in the critically ill pop-

See the Related Editorial on Page 577

ulation. ${ }^{1-3}$ Historically the mainstay of therapy, invasive ventilation with a low tidal volume strategy has been employed while the underlying etiology of respiratory failure were investigated and treated. ${ }^{4}$ To first do no harm requires evaluation of the patient's respiratory system mechanics and determining ventilator settings that balance the need for adequate gas exchange with the minimization of risk for patient-selfinflicted or ventilator-induced lung injury. Advances in noninvasive ventilation (NIV) and high-flow nasal cannula (HFNC) technology have led to a resurgence of interest in these modalities, even in early ARDS, with promising results. ${ }^{5}$ The role for NIV/HFNC in more severe cases of acute respiratory failure remains controversial, as patients who fail such therapy have a poorer prognosis, and the delay in escalation to intubation and mechanical ventilation for the sickest patients - defined as severe $\left(\mathrm{P}_{\mathrm{aO}_{2}} / \mathrm{F}_{\mathrm{IO}_{2}}<100\right)$ hypoxemia and ARDS - has been shown to increase mortality. ${ }^{6,7}$

A lung-protective ventilation strategy in 2019 is generally accepted to include a personalized, open-lung approach that attempts to match patient ventilator needs while minimizing tidal volume and driving pressure. Much of the current clinical and translational literature focuses on methods for sizing Gattinoni's "baby lung" and selecting an appropriate PEEP in real-time at the bedside. ${ }^{8,9}$ Less is understood about what to do when these parameters have been optimized but the patient fails to improve or fails a conventional lung-protective ventilation strategy.

A retrospective survey of medical, surgical, and subspecialty ICUs in our quaternary medical center identified a small subset $(15 \%)$ of the total cases of ARDS that met criteria for severe and refractory hypoxemia. ${ }^{10}$ Fewer than half of this population received what would be considered nonconventional ventilatory approaches or rescue therapies (eg, prone positioning, inhaled prostaglandins or nitric oxide, airway pressure release ventilation, high-frequency oscillation, extracorporeal life support) during their hospitalization, yet mortality remained well below expected in the 15-20\% range, which suggests that perhaps a portion of this group was misidentified as severe and/or refractory

Correspondence: Richard A Oeckler MD PhD, 200 First Street SW, Rochester, MN, 55905. E-mail: oeckler.richard@mayo.edu.

DOI: $10.4187 /$ respcare. 07243

\section{QUICK LOOK}

\section{Current knowledge}

ARDS remains a source of high morbidity and mortality among the critically ill. Nonconventional ventilatory approaches such as prone positioning have been shown to improve mortality if implemented correctly and in a timely fashion.

\section{What this paper contributes to our knowledge}

We evaluated the implementation of a refractory hypoxemia protocol on the mechanical ventilation and proning practices at our institution. We observed that subjects with true refractory hypoxemia were identified earlier and time to proning was significantly shortened.

based upon a suboptimal ventilation strategy. Of those who did receive rescue therapies, the average time to implementation ranged between 1-2.5 d after the criteria for refractory hypoxemia had been met. Moreover, there was no clear rationale for the form of rescue therapy employed, although this may have been due to a lack of data predating several important studies for or against specific modalities in ARDS, including prone positioning, neuromuscular blockade, and high-frequency oscillation.

Because of the multidisciplinary approach to care (including shift changes and handoffs) and the often chaotic nature of the ICU setting (eg, multiple severely ill patients, planned and unplanned distractions and emergencies including code and rapid response activations, decompensating patients, family care conferences), our hypothesis was that a protocolized approach to mechanical ventilation with partially automated and clearly defined thresholds for management changes would allow for the rapid delivery of a safe and optimized ventilation strategy for most patients, and for the identification of patients with true severe and refractory hypoxemia in a timely fashion. Our aims included identifying true and severe hypoxemia in a timely fashion and decreasing the time to escalation and rescue therapy implementation. Such strategies are consistent with current evidence for early interventions improving outcomes in several studies including early paralysis or prone positioning. ${ }^{11-15}$

\section{Methods}

After fully analyzing the study results, and recognizing the recent shifts in the available evidence base for rescue strategies, in 2014 we convened a multidisciplinary working group composed of critical care physicians (pulmonary critical care, anesthesia critical care, extracorporeal membrane oxygenation [ECMO] specialists), respiratory therapists, clinical nurse specialists, nurses, and other key 

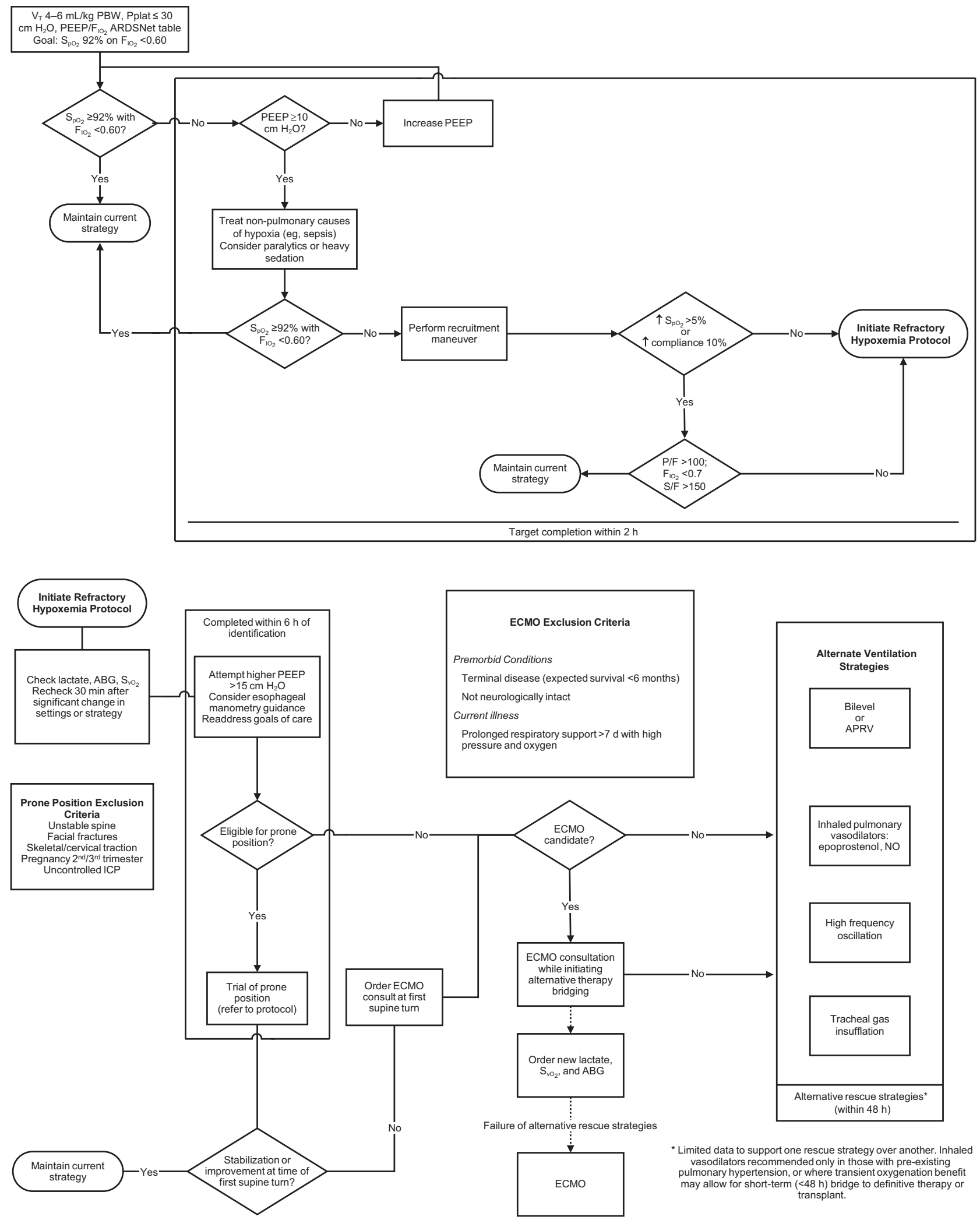

Fig. 1. Refractory hypoxemia protocol. $\mathrm{PBW}=$ predicted body weight; $\mathrm{P}_{\text {plat }}=$ plateau pressure; $\mathrm{ABG}=$ arterial blood gas; $\mathrm{ICP}=\mathrm{intracranial}$ pressure; $\mathrm{ECMO}=$ extracorporeal membrane oxygenation; $\mathrm{APRV}=$ airway pressure release ventilation; $\mathrm{NO}=$ nitric oxide. 


\section{Early Protocolized Mechanical Ventilation in ARDS}

stakeholders to develop expert consensus for an evidencebased, best-practice guideline for mechanical ventilation within our institution (Fig. 1). We initially identified 2 key areas for improvement. The first area was the correct identification of patients with true severe and refractory hypoxemia, not simply those under-recruited or inappropriately under-ventilated. For the former, it was concluded that a delay in, and misidentification of, these patients has historically likely been due to the absence of a consensus definition for refractory hypoxemia. Recent advancement in this area has been aided by a recent national survey of $>400$ multidisciplinary critical care providers ${ }^{10}$ that proposed consensus for defining severe and refractory hypoxemia as either a $\mathrm{P}_{\mathrm{aO}_{2}} / \mathrm{F}_{\mathrm{IO}_{2}}<100 \mathrm{~cm}$ $\mathrm{H}_{2} \mathrm{O}$ or $\mathrm{P}_{\mathrm{aO}_{2}}<60$ and $\mathrm{F}_{\mathrm{IO}_{2}}>0.7$ for $1 \mathrm{~h}$ with PEEP $\geq 15$, having ruled out reversible causes. The second area is that patients with severe and refractory hypoxemia are not escalated to nonconventional or rescue strategies in a timely, evidenced-based fashion.

This study was performed at the Mayo Clinic in Rochester, Minnesota, and was approved by the Mayo Clinic Institutional Review Board. All adult patients $\geq 18 \mathrm{y}$ old admitted to the adult ICUs at our institution and diagnosed with ARDS in accordance to the 2012 Berlin definition, ${ }^{16}$ who were treated according to our institution's refractory hypoxemia protocol (Fig. 1) between December 2013 and August 2016, were included, provided they had provided consent for research in their medical record. Those dates were chosen to reflect 16 months before and 16 months after the implementation of the refractory hypoxemia protocol. The protocol was implemented in April 2015; subjects treated from December 2013 through March 2015 were classified as the before group, and those who were treated from April 2015 through August 2016 were classified as the after-implementation group.

A sustained inflation recruitment maneuver was performed: starting PEEP was the current setting, or $5 \mathrm{~cm} \mathrm{H}_{2} \mathrm{O}$ below the current setting, if feasible. Top pressure was set at $40 \mathrm{~cm} \mathrm{H}_{2} \mathrm{O}$, and ramp speed was set at $3 \mathrm{~cm} \mathrm{H}_{2} \mathrm{O} / \mathrm{s}$. A 10 -s pause was set at the end of each maneuver. ${ }^{17-19}$

Subjects with ARDS were identified using billing codes for the diagnosis of ARDS and hypoxemic respiratory failure. Their charts were then reviewed by an expert to confirm that the Berlin criteria were met. ${ }^{16}$ Subjects who had been proned were identified using billing codes for the use of a RotoProne specialty bed (KCI, San Antonio, Texas) and using ICU records of subjects who were manually proned. To identify the time to proning and the duration of proning sessions, subjects' activity forms were reviewed. Patient activities are charted by bedside nurses on an hourly basis; this is the standard way of recording prone positioning at our institution. Initial time of proning was defined as the first time the word prone appeared on the activity
Table 1. Baseline characteristics of all subjects with ARDS

\begin{tabular}{|c|c|c|c|}
\hline Variables & Pre-protocol & Post-protocol & $P$ \\
\hline Sex, male & $62(26.5)$ & $68(29)$ & .93 \\
\hline Age, y & $58.8(32-78.6)$ & $60.7(37-79.3)$ & .09 \\
\hline Body mass index, $\mathrm{kg} / \mathrm{m}^{2}$ & $27.9(19.7-39.4)$ & $28.6(22.7-41.5)$ & .25 \\
\hline $\mathrm{P}_{\mathrm{aO}_{2}} / \mathrm{F}_{\mathrm{IO}_{2}}$ & $105(63.3-176.7)$ & $107(67-168.2)$ & .77 \\
\hline ARDS severity & & & .87 \\
\hline Mild & $5(4.5)$ & $5(4.1)$ & \\
\hline Moderate & $55(49.1)$ & $64(52.5)$ & \\
\hline Severe & $52(46.4)$ & $53(43.4)$ & \\
\hline PEEP & $10(7.5-15)$ & $11.25(8-16)$ & .23 \\
\hline Driving pressure, $\mathrm{cm} \mathrm{H}_{2} \mathrm{O}$ & $14(7-23)^{*}$ & $14(9-22.6) \dagger$ & .52 \\
\hline $\begin{array}{l}\text { Tidal volume, } \mathrm{ml} / \mathrm{kg} / \text { Body } \\
\text { weight }\end{array}$ & $5.05(3.5-6.5)$ & $4.8(3.4-6.6)$ & .34 \\
\hline Proned, $n(\%)$ & $12(10)$ & $16(13)$ & .56 \\
\hline ECMO consult & $10(8.9)$ & $5(4.1)$ & .13 \\
\hline APACHE III score & $47(26.3-92)$ & $47(25.3-84.6)$ & .14 \\
\hline SOFA score & $9(5-14)$ & $9.5(4-14)$ & .29 \\
\hline ICU length of stay, $d$ & $7.9(3.7-20.7)$ & $7.4(2.9-21)$ & .45 \\
\hline Hospital length of stay, $d$ & $15.6(5.5-37.6)$ & $15(3.8-42)$ & .39 \\
\hline ICU mortality, \% & $40(35.7)$ & $48(39.4)$ & .56 \\
\hline Hospital mortality, $\%$ & $48(42.8)$ & $62(50.8)$ & .22 \\
\hline \multicolumn{4}{|c|}{$\begin{array}{l}\text { Data are presented as median (interquartile range) or } n \text { (\%). Pre-protocol: } n=112 \text { subjects; } \\
\text { Post-protocol: } n=122 \text { subjects. } \\
* n=83 \text { subjects. } \\
\dagger n=103 \text { subjects. } \\
\text { APACHE = Acute Physiology and Chronic Health Evaluation III } \\
\text { SOFA = Sequential Organ Failure Assessment }\end{array}$} \\
\hline
\end{tabular}

section of subjects' charts, and end time was the last such entry on the subjects' charts.

Clinical data obtained from retrospective chart review included age, gender, Acute Physiology and Chronic Health Evaluation III (APACHE III) and Sequential Organ Failure Assessment (SOFA) scores at admission to the ICU; body mass index, tidal volume, PEEP, $\mathrm{P}_{\mathrm{aO}_{2}} / \mathrm{F}_{\mathrm{IO}_{2}}$, respiratory system driving pressures, and ICU and hospital mortality and length of stay at $2 \mathrm{~h}$ from identification of hypoxemia. For the subjects who were proned, the same baseline characteristics were obtained, as well as time from hypoxemia to the initiation and duration of each proning session. Only patients receiving volume-control mode of ventilation were included in the analysis.

\section{Statistical Analysis}

Data were collected and analyzed using JMP 10.0.0 (SAS Institute, Cary, North Carolina). Normally distributed continuous variables were summarized with means and standard deviations. Non-normally distributed variables were summarized with medians and interquartile range (IRQ). Correlations between subjects who were proned before and after the institution of the refractory hypoxemia protocol and their outcomes were calculated using the nonparametric Wilcoxon test. Categorical data were summarized with 


\section{Early Protocolized Mechanical Ventilation in ARDS}

Table 2. Outcomes of subjects with refractory hypoxemia who were proned

\begin{tabular}{|c|c|c|c|}
\hline & Pre-protocol & Post-protocol & $P$ \\
\hline $\begin{array}{l}\text { APACHE III score at } \\
\text { proning }\end{array}$ & $64.5(25-114)$ & $44(23-93)$ & .32 \\
\hline Tidal volume, $\mathrm{mL} / \mathrm{kg}$ & $5(3-8)$ & $5(3-6)$ & .42 \\
\hline PEEP at proning, $\mathrm{cm} \mathrm{H}_{2} \mathrm{O}$ & $12.5(6.5-19.4)$ & $18(10-22)$ & .04 \\
\hline Driving pressure at proning & $16(13-36.2)$ & $12(9-19.6)$ & .031 \\
\hline Body mass index, $\mathrm{kg} / \mathrm{m}^{2}$ & $24.25(18.1-53.9)$ & $29.5(17.2-44.3)$ & .09 \\
\hline $\mathrm{P}_{\mathrm{aO}_{2}} / \mathrm{F}_{\mathrm{IO}_{2}}$ at proning & $65(36-140.8)$ & $78(33-190)$ & .45 \\
\hline $\begin{array}{l}\mathrm{P}_{\mathrm{aO}_{2}} / \mathrm{F}_{\mathrm{IO}_{2}} \text { at } 1 \mathrm{~h} \text { after } \\
\text { proning }\end{array}$ & $104(47-176)$ & $115(63-303)$ & .048 \\
\hline $\begin{array}{l}\text { Mechanical ventilation } \\
\text { hours after proning }\end{array}$ & $95.5(1-547.9)$ & $31(18.4-327)$ & .51 \\
\hline $\begin{array}{l}\text { Time from hypoxia to } \\
\text { proning, } h\end{array}$ & $42.2(6.83-347.2)$ & $16.3(1-99.7)$ & .007 \\
\hline $\begin{array}{l}\text { Duration of proning } \\
\text { sessions, } \mathrm{h}\end{array}$ & $3(2-4.4)$ & $4(2-15)$ & .12 \\
\hline ICU length of stay, $d$ & $14.3(2-35)$ & $6(1-16)$ & .028 \\
\hline Hospital length of stay, $d$ & $21.9(2.26-64.1)$ & $7.48(2.25-3.45)$ & .08 \\
\hline ICU mortality & $7(58)$ & $9(56)$ & .65 \\
\hline Hospital mortality & $8(66)$ & $11(68)$ & .89 \\
\hline
\end{tabular}

frequencies and percentages, with correlations made using a 2-tailed Fisher exact test. A $P$ value of $<.05$ was considered statistically significant for all calculations.

\section{Results}

Patients with a diagnosis of ARDS who required a $\mathrm{F}_{\mathrm{IO}_{2}}>$ $60 \%$, despite lung recruitment and PEEP titration per protocol, for $>2 \mathrm{~h}$ were analyzed for the implementation of prone positioning; their baseline characteristics are described in Table 1. Of those, 28 subjects received prone positioning, and they form our study cohort (Table 2).

Baseline demographics, ARDS severity, $\mathrm{P}_{\mathrm{aO}_{2}} / \mathrm{F}_{\mathrm{IO}_{2}}$, tidal volume, PEEP, and driving pressure at the time of refractory hypoxemia diagnosis, APACHE 3 and SOFA scores, ICU and hospital LOS and mortality are presented in Table 1 . The groups were similar in their baseline characteristics and variables of interest at the time of diagnosis of refractory hypoxemia.

Table 2 demonstrates baseline characteristics and the variables of interest of subjects who were proned before and after the protocol implementation. Body mass index, APACHE scores, tidal volumes, $\mathrm{P}_{\mathrm{aO}} / \mathrm{F}_{\mathrm{IO}_{2}}$, duration of ventilation after proning, and mortality were similar in both groups. PEEP at the time of proning was higher after the protocol implementation $\left(12.5 \mathrm{~cm} \mathrm{H}_{2} \mathrm{O}\right.$ vs $18 \mathrm{~cm}$ $\mathrm{H}_{2} \mathrm{O}, P=.038$ ). Driving pressure was lower at the time of proning $\left(16 \mathrm{~cm} \mathrm{H}_{2} \mathrm{O}\right.$ vs $\left.12 \mathrm{~cm} \mathrm{H}_{2} \mathrm{O}, P=.031\right)$ after protocol implementation. Time from hypoxemia to proning was shorter after protocol implementation (42.2 $\mathrm{h}$ vs $16.3 \mathrm{~h}, P=.007) . \mathrm{P}_{\mathrm{aO}_{2}} / \mathrm{F}_{\mathrm{IO}_{2}}$ at $1 \mathrm{~h}$ after proning was higher after the implementation of the protocol (104 vs $115, P=.048)$. ICU length of stay ( $14.3 \mathrm{~d}$ vs $6 \mathrm{~d}, P=$ $.04)$ and hospital length of stay $(21.9 \mathrm{~d}$ vs $7.5 \mathrm{~d}, P=.08)$ were shorter after the protocol implementation. Before protocol implementation, 17 subjects required respiratory ECMO (1.0 respiratory ECMO case per month) compared to 13 subjects after protocol implementation (0.76 respiratory ECMO cases per month $)(P=.30)$.

\section{Discussion}

The implementation of a severe refractory hypoxemia protocol significantly decreased the time to optimization of conventional ventilation and led to earlier identification of patients with severe or refractory hypoxemia resulting in escalation to prone positioning. PEEP levels were higher and airway driving pressures (ie, the difference between plateau pressure and PEEP) were lower in subjects after protocol implementation. Although ICU length of stay was reduced, overall survival was not affected.

The prone position is an attractive intervention in patients with $\mathrm{ARDS}^{20}$ for several physiologic-based reasons, including homogenization of $\dot{\mathrm{V}} / \dot{\mathrm{Q}}$, unloading of mediastinal contents, improved airway drainage, and improved oxygenation compared to the supine position. ${ }^{21,22}$ Multiple randomized controlled trials ${ }^{15,23,24}$ have tested the role of prone positioning in survival of subjects with ARDS, with a consistent signal toward mortality benefit in the sickest subjects with severe $\left(\mathrm{P}_{\mathrm{aO}} / \mathrm{F}_{\mathrm{IO}_{2}}<100 \mathrm{~mm} \mathrm{Hg}\right)$ or very severe $\left(\mathrm{P}_{\mathrm{aO}_{2}} / \mathrm{F}_{\mathrm{IO}_{2}}<50\right)$ ARDS. To accomplish this, patients have traditionally been manually proned and each prone session lasted $17 h^{15,23}$ or 18 $\mathrm{h}^{24}$ In contrast, at our institution the method of proning has been inconsistent, with some ICUs utilizing a specialty rotational bed, whereas others proned patients manually. This could explain in part the discrepancy in duration of proning sessions. With initial proning sessions lasting an average of 4 $\mathrm{h}$, subjects were moved to the supine position for $0.5-4 \mathrm{~h}$ between sessions for various reasons, including necessary care, emergent procedures and tests, and treating intensivists' preference. Even though the time to proning was reduced after the protocol implementation, we didn't observe the same mortality benefits observed in the aforementioned trials. The lack of mortality benefit could be due to our study being underpowered to identify such a difference.

We defined refractory hypoxemia as a failure to increase $\mathrm{S}_{\mathrm{pO}_{2}}$ by $5 \%$ or to decrease $\mathrm{F}_{\mathrm{IO}_{2}}$ to below $60 \%$ (or both), despite a PEEP of at least $15 \mathrm{~cm} \mathrm{H}_{2} \mathrm{O}$ and dynamic optimization of ventilator settings for $120 \mathrm{~min}$ following intubation. The goal was to optimize ventilator settings and to address asynchrony, compliance, and oxygen consumption with sedation and paralytics, while treating underlying causes of respiratory failure at $2 \mathrm{~h}$ post-intubation or upon arrival to 


\section{Early Protocolized Mechanical Ventilation in ARDS}

our ICU (Fig. 1). The implementation of the refractory hypoxemia protocol significantly decreased the time to diagnosis of refractory hypoxemia, as well as the time from diagnosis to proning. Although these benefits may be explained simply by the stepwise, standardized approach to mechanical ventilation primarily driven by respiratory therapists, who are less susceptible to the plethora of distractions that a primary medical provider is exposed to during an ICU shift, the extensive communication and education surrounding the refractory hypoxemia protocol rollout likely increased overall awareness of the multidisciplinary ICU teams. We are encouraged to note that, after protocol implementation, our institution achieved a median time to proning similar to the protocols of the randomized controlled trials that have reported a mortality improvement. ${ }^{11,14,15}$ Our findings reveal, however, that our practice diverges from those studies beyond the initial move to proning, specifically with regard to duration of proning before returning to a supine position and the overall practice variation in the approach to the prone position. By addressing these issues, future protocol modification may be able to further affect patient outcomes.

Our subjects' $\mathrm{P}_{\mathrm{aO}} / \mathrm{F}_{\mathrm{IO}_{2}}$ values at the time of proning was significantly lower than those of the aforementioned trials. At time of proning, our subjects' median $\mathrm{P}_{\mathrm{aO}_{2}} / \mathrm{F}_{\mathrm{IO}_{2}}$ values were 70-72.2 $\mathrm{mm} \mathrm{Hg}$, compared to $147 \mathrm{~mm} \mathrm{Hg}$ in the study by Mancebo et $\mathrm{al}^{23}$ and $150 \mathrm{~mm} \mathrm{Hg}$ in the studies by Taccone et $\mathrm{al}^{24}$ and Guérin et al. ${ }^{15}$ Admission SOFA scores in our cohort suggest a similar overall severity of illness.

Respiratory system driving pressure can be calculated for mechanically ventilated patients who are not making inspiratory efforts as the difference between plateau pressure and total PEEP. ${ }^{25}$ Traditionally, a lung-protective ventilation strategy includes scaling tidal volume to predicted body weight to normalize tidal volume to lung size. However, in patients with ARDS, the "baby lung," which is the proportion of lung available for ventilation (and likely with normal lung compliance), is markedly decreased, as reflected by lower respiratory-system compliance. ${ }^{9,26-28}$ Normalizing tidal volume to respiratory-system compliance (ie the driving pressure) has been shown to be a more accurate predictor of safe ventilation targeting the "baby lung" and resulting in improved outcomes compared to tidal volume selected by ideal body weight in patients with ARDS. ${ }^{25}$ Although this work was published after our study began, our subjects' driving pressures were significantly lower after protocol implementation, which is likely a consequence of specific checkpoints favoring lung recruitment and increased PEEP based on bedside measurements of lung mechanics within the protocol.

Improvement in $\mathrm{P}_{\mathrm{aO}} / \mathrm{F}_{\mathrm{IO}_{2}}$ with proning was also significant after the implementation of this protocol. This finding is not surprising, considering the evidence supporting proning as an advanced method of ventilation. ${ }^{11,13,29}$ This finding corroborates the aforementioned evidence and indicates that prone positioning is effective in improving oxygenation. However, as the current evidence shows, duration of proning sessions matters when analyzing outcomes.

We are unable to explain the decreased ICU and hospital length of stay noted in our findings. We can say that they may be related to the high mortality found in the ARDS population, but our initial objectives didn't include looking into causes of death for the subjects who were included in this study.

Our study has several limitations. First, this is a singlecenter, pre/post study without randomization and included subjects admitted to medical, surgical, and medical-surgical ICUs that adopted the refractory hypoxemia protocol. As such, the population is heterogeneous. Second, our population is very small, and speaks to the high standard of care and the state of our practice at baseline. Few patients, when optimized early and followed closely with appropriate changes, qualify as refractory. Overall, our incidence of ARDS and particularly patient self-inflicted/ventilatorinduced lung injury continue to decline. ${ }^{30}$ As such, our study was likely underpowered to detect a change in mortality. Conversely, the parameters associated with an accepted evidence-based lung-protective ventilation strategy improved, suggesting that a respiratory therapy-driven protocolized approach to ventilation is both feasible and achievable in the clinical setting. Third, the concept of driving pressure and the association of a mortality improvement when limited to $<15-19 \mathrm{~cm} \mathrm{H}_{2} \mathrm{O}$ was not established at the time our protocol was developed. The work group is currently in the process of revising our protocol based on these data and several other studies since the 2012-2015 development period, and we will be deploying the modifications for study in the next 6-12 months. Fourth, we cannot prove that the statistically significant results are directly related to implementation of the protocol. The retrospective nature of this study combined with practice variations, including ultimate decision to use and how to implement advanced modalities of mechanical ventilation remains the purview of the ICU attending physician.

\section{Conclusions}

Our study indicates that an early protocolized approach to personalized mechanical ventilation results in a more rapid achievement of parameters currently identified as key to a lung-protective ventilation strategy, including increased PEEP and lower airway driving pressure. By rapidly optimizing conventional ventilation, subjects with severe and refractory hypoxemia are identified earlier, which results in earlier proning and reduced need to escalate to extracorporeal support, potentially leading to shorter ICU and hospital lengths of stay. A suboptimal proning approach (eg, 3-4 actual vs 16-18 targeted h per proning session) may explain the lack of mortality benefit 


\section{Early Protocolized Mechanical Ventilation in ARDS}

in our study, and this has been identified as a target for future process improvement.

\section{REFERENCES}

1. Bellani G, Laffey JG, Pham T, Fan E, Brochard L, Esteban A, et al. Epidemiology, patterns of care, and mortality for patients with acute respiratory distress syndrome in intensive care units in 50 countries. Jama 2016;315(8):788-800.

2. Esteban A, Frutos-Vivar F, Muriel A, Ferguson ND, Peñuelas O, Abraira $\mathrm{V}$, et al. Evolution of mortality over time in patients receiving mechanical ventilation. Am J Respir Crit Care Med 2013;188(2):220-230.

3. Villar J, Blanco J, Añón JM, Santos-Bouza A, Blanch L, Ambrós A, et al. The ALIEN study: incidence and outcome of acute respiratory distress syndrome in the era of lung protective ventilation. Intensive Care Med 2011;37(12):1932-1941.

4. Acute Respiratory Distress Syndrome Network, Brower RG, Matthay MA, Morris A, Schoenfeld D, Thompson BT, Wheeler A. Ventilation with lower tidal volumes as compared with traditional tidal volumes for acute lung injury and the acute respiratory distress syndrome. N Engl J Med 2000;342(18):1301-1308.

5. Frat JP, Thille AW, Mercat A, Girault C, Ragot S, Perbet S, et al. High-flow oxygen through nasal cannula in acute hypoxemic respiratory failure. N Engl J Med 2015;372(23):2185-2196.

6. Kang BJ, Koh Y, Lim CM, Huh JW, Baek S, Han M, et al. Failure of high-flow nasal cannula therapy may delay intubation and increase mortality. Intensive Care Med 2015;41(4):623-632.

7. Kangelaris KN, Ware LB, Wang CY, Janz DR, Zhuo H, Matthay MA, et al. Timing of intubation and clinical outcomes in adults with acute respiratory distress syndrome. Crit Care Med 2016;44(1):120-129.

8. Cherpanath TG, Smeding L, Hirsch A, Lagrand WK, Schultz MJ, Groeneveld AB. Low tidal volume ventilation ameliorates left ventricular dysfunction in mechanically ventilated rats following LPSinduced lung injury. BMC Anesthesiol 2015;15:140.

9. Gattinoni L, Pesenti A. The concept of baby lung. Intensive Care Med 2005;31(6):776-784.

10. Alhurani RE, Oeckler RA, Franco PM, Jenkins SM, Gajic O, Pannu SR. refractory hypoxemia and use of rescue strategies: a U.S. national survey of adult intensivists. Ann Am Thorac Soc 2016;13(7):1105-1114.

11. Guerin C, Gaillard S, Lemasson S, Ayzac L, Girard R, Beuret P, et al. Effects of systematic prone positioning in hypoxemic acute respiratory failure: a randomized controlled trial. JAMA 2004;292(19):2379-2387.

12. Guerin C, Gattinoni L. Assessment of oxygenation response to prone position ventilation in ARDS by lung ultrasonography. Intensive Care Med 2016;42(10):1601-1603.

13. Guerin C, Mancebo J. Prone positioning and neuromuscular blocking agents are part of standard care in severe ARDS patients: yes. Intensive Care Med 2015;41(12):2195-2197.

14. Guérin C, Reignier J, Richard JC. Prone positioning in the acute respiratory distress syndrome. N Engl J Med 2013;369(10):980-981.

15. Guérin C, Reignier J, Richard JC, Beuret P, Gacouin A, Boulain T, et al. Prone positioning in severe acute respiratory distress syndrome. N Engl J Med 2013;368(23):2159-2168.
16. Ranieri VM, Rubenfeld GD, Thompson BT, Ferguson ND, Caldwell E, Fan E, et al. Acute respiratory distress syndrome: the Berlin definition. JAMA 2012;307(23):2526-2533.

17. Arnal JM, Paquet J, Wysocki M, Demory D, Donati S, Granier I, et al. Optimal duration of a sustained inflation recruitment maneuver in ARDS patients. Intensive Care Med 2011;37(10):1588-1594.

18. Borges JB, Okamoto VN, Matos GF, Caramez MP, Arantes PR, Barros F, et al. Reversibility of lung collapse and hypoxemia in early acute respiratory distress syndrome. Am J Respir Crit Care Med 2006; 174(3):268-278.

19. Cressoni M, Chiumello D, Algieri I, Brioni M, Chiurazzi C, Colombo $\mathrm{A}$, et al. Opening pressures and atelectrauma in acute respiratory distress syndrome. Intensive Care Med 2017;43(5):603-611.

20. Guerin C. Prone position. Curr Opin Crit Care 2014;20(1):92-97.

21. Sud S, Friedrich JO, Adhikari NK, Taccone P, Mancebo J, Polli F, et al. Effect of prone positioning during mechanical ventilation on mortality among patients with acute respiratory distress syndrome: a systematic review and meta-analysis. CMAJ 2014;186(10):E381E390.

22. Sud S, Friedrich JO, Taccone P, Polli F, Adhikari NK, Latini R, et al. Prone ventilation reduces mortality in patients with acute respiratory failure and severe hypoxemia: systematic review and meta-analysis. Intensive Care Med 2010;36(4):585-599.

23. Mancebo J, Fernández R, Blanch L, Rialp G, Gordo F, Ferrer M, et al. A multicenter trial of prolonged prone ventilation in severe acute respiratory distress syndrome. Am J Respir Crit Care Med 2006;173 (11):1233-1239.

24. Taccone P, Pesenti A, Latini R, Polli F, Vagginelli F, Mietto C, et al. Prone positioning in patients with moderate and severe acute respiratory distress syndrome: a randomized controlled trial. JAMA 2009; 302(18):1977-1984.

25. Amato MB, Meade MO, Slutsky AS, Brochard L, Costa EL, Schoenfeld DA, et al. Driving pressure and survival in the acute respiratory distress syndrome. N Engl J Med 2015;372(8):747-755.

26. Gattinoni L, Pesenti A, Bombino M, Baglioni S, Rivolta M, Rossi F, et al. Relationships between lung computed tomographic density, gas exchange, and PEEP in acute respiratory failure. Anesthesiology 1988;69(6):824-832.

27. Terragni PP, Filippini C, Slutsky AS, Birocco A, Tenaglia T, Grasso $S$, et al. Accuracy of plateau pressure and stress index to identify injurious ventilation in patients with acute respiratory distress syndrome. Anesthesiology 2013;119(4):880-889.

28. Terragni PP, Rosboch G, Tealdi A, Corno E, Menaldo E, Davini O, et al. Tidal hyperinflation during low tidal volume ventilation in acute respiratory distress syndrome. Am J Respir Crit Care Med 2007;175(2):160-166.

29. Guerin C. Prone positioning: do not turn it off!. Intensive Care Med 2005;31(8):1012-1013.

30. Li G, Malinchoc M, Cartin-Ceba R, Venkata CV, Kor DJ, Peters SG, et al. Eight-year trend of acute respiratory distress syndrome: a population-based study in Olmsted County, Minnesota. Am J Respir Crit Care Med 2011;183(1):59-66.

This article is approved for Continuing Respiratory Care Education credit. For information and to obtain your CRCE

(free to AARC members) visit www.rcjournal.com

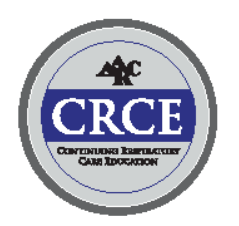

